\title{
Verapamil reduced attack frequency and the use of abortive agents in episodic cluster headache
}

Leone M, D'Amico D, Frediani F, et al. Verapamil in the prophylaxis of episodic cluster headache: a double-blind study versus placebo. Neurology 2000 Mar;54:1382-5.

\section{QUESTION: What is the effectiveness of verapamil as a prophylaxis for episodic cluster headache?}

\section{Design}

Randomised \{allocation concealed $*\}, \uparrow$ blinded \{clinicians, patients, and outcome assessors*\}, $\uparrow$ placebo controlled trial with 2 week follow up.

\section{Setting \\ 3 outpatient clinics in Italy.}

\section{Patients}

30 adults between 18 and 60 years of age (mean age $44 \mathrm{y}, 90 \%$ men) who were outpatients and had a diagnosis of episodic cluster headache (International Headache Society criteria) with $\geqslant 1$ previous cluster period lasting $\geqslant 1$ month and who had been in a cluster period for $\leqslant 10$ days and had an expected duration of the remainder of the cluster period of $\geqslant 20$ days. Exclusion criteria were liver or kidney disease, cardiopathological findings contraindicating verapamil use, psychiatric disorder, use of antidepressants or antipsychotics, drug or alcohol abuse, or previous adynamic ileus. Follow up was $100 \%$.

\section{Intervention}

After a 5 day run-in period, patients were allocated to verapamil, $120 \mathrm{mg} 3$ times/day $(\mathrm{n}=15)$, or placebo, 3 times/day $(\mathrm{n}=15)$, for 2 weeks.

\section{Main outcome measures}

Self reported frequency of cluster headache attacks and use of abortive agents.

\section{Main results}

During the first week of treatment, the verapamil and placebo groups did not differ for median numbers of attacks/day (1.1 $v 1.7)$ or abortive agents used/day (1.0 v 1.2). During the second week of treatment, verapamil was more effective than placebo in reducing both the number of attacks (median $0.6 v 1.65 / \mathrm{d}, \mathrm{p}<0.001$ ) and the number of abortive agents used (median $0.5 v 1.2 / \mathrm{d}$, $\mathrm{p}<0.004)$. Fewer patients in the verapamil group than in the placebo group were non-responders (ie, having a $\leqslant 50 \%$ reduction in attack frequency) $\{\mathrm{p}<0.001\} \ddagger$ (table). Side effects experienced during the treatment period were mild.

\section{Conclusion}

Verapamil reduced attack frequency and the use of abortive agents in patients with episodic cluster headache.

*See glossary

†nformation provided by author.

末p Value calculated from data in article.

\section{COMMENTARY}

Treatment of cluster headache includes aborting any current headache and prophylaxis to prevent headaches both during the current cluster and in future clusters. Of the drugs used for prophylactic treatment, prednisone is the most studied. 1 blinded, crossover study and several unblinded studies showed that prednisone completely stopped cluster headaches in $60 \%{ }^{1}$ to $90 \% 0^{2}$ of patients.

This randomised controlled trial by Leone $e t a l$ adds to the sparse literature on prophylaxis of cluster headaches. As with many studies of cluster headaches, this study used a small sample size and had a short follow up duration, but it appears to have valid results.

The study confirms that verapamil is an effective alternative for the prophylaxis of cluster headaches. In the absence of a direct comparison between verapamil and prednisone, verapamil is the first choice for patients requiring frequent prophylaxis. The choice for infrequent prophylaxis should depend on a patient's previous experience and potential for drug related adverse effects. We now need a study with a factorial design that compares verapamil, prednisone, and their combination.

A previous study showed that verapamil is more effective than lithium and has fewer side effects.. Although methysergide is commonly prescribed, no controlled trials have compared this drug with placebo or verapamil.

Robert Badgett, MD University of Texas Health Sciences Center San Antonio, Texas, USA

1 Couch JR Jr, Ziegler DK. Prednisone therapy for cluster headache. Headache 1978;18:219-21.

2 Jammes JL. The treatment of cluster headaches with prednisone. Dis Nerv Syst 1975;36:375-6.

3 Bussone G, Leone M, Peccarisi C, et al. Double blind comparison of lithium and verapamil in cluster headache prophylaxis. Headache 1990;30:411-7. 